\title{
Defining the gap in epicardial pulmonary vein connectivity with high density mapping
}

\author{
Mark Davies ${ }^{1}$ and Kim Rajappan ${ }^{1}$ \\ ${ }^{1}$ Oxford University Hospitals NHS Foundation Trust
}

June 15, 2021

\section{Hosted file}

Editorial final.docx available at https://authorea.com/users/419831/articles/526205-definingthe-gap-in-epicardial-pulmonary-vein-connectivity-with-high-density-mapping 